\title{
Call for recently completed Masters and Ph.Ds
}

We would like to profile Master's and Doctoral theses that have been completed in the area of Outdoor Education in Australasia. This is an opportunity to profile outdoor education research. It is also a valuable resource to researchers, students and practitioners in outdoor education.

If you have graduated with a Master's or Ph.D since 2005 you are invited to submit the following information:
Author

Title

100 word synopsis of your thesis

Supervisor/s

Institution which awarded your degree

Address of electronic file of thesis (if available)

Contact email:

Please forward this information to Robyn Zink at ajoe@outdoorcouncil.asn.au

\section{Call for photos and artwork}

Do your students or children draw about their time in the outdoors or take photos of things they like in the outdoors? Or do you have photos of people enjoying their learning experiences in the outdoors? We want to include a range of these images on the cover of the Australian Journal of Outdoor Education. If you have an image that expresses something about outdoor education that you think would look great on the cover of the journal send it to us at:

\author{
Queensland Outdoor Recreation Federation \\ Sports House \\ 150 Caxton Street \\ Milton QLD, 4064 \\ Australia
}

Or email a scanned image to Robyn Zink at ajoe@ outdoorcouncil.asn.au
If you are sending a photo with people that are recognisable please ensure you have secured permission from those people for that image to be used on the cover of the journal.

I look forward to receiving your contributions. All original artwork will be returned to the sender.

Thanks

Robyn Zink

Editor 